\title{
Modified suprascapular nerve block with bupivacaine alone effectively controls chronic shoulder pain in patients with rheumatoid arthritis
}

\author{
Kamel Gado, Paul Emery
}

\begin{abstract}
Chronic shoulder pain is a common and disabling symptom in patients with rheumatoid arthritis (RA). It has been previously shown that a suprascapular nerve block (SSNB) using the standard mixture of bupivacaine and adrenaline (Ba) plus methylprednisolone (P), which is routinely used in pain clinics, results in a considerable improvement in pain relief and range of movement compared with conventional intra-articular steroid injections in such patients. A double blind study was carried out in 29 patients (58 shoulders) with RA to compare SSNB induced with $\mathrm{Ba}$ alone with that induced using the conventional mixture of Ba plus P. Highly significant improvements were noted in measures of pain, stiffness, and range of most movements for both treatments (up to three months) compared with baseline. Results favoured $\mathrm{Ba}$ alone; the differences between the two treatments reached statistical significance for stiffness (at 12 weeks) and active abduction (at one week). It is concluded that the addition of $P$ to the SSNB mixture confers no benefit in these patients.
\end{abstract}

(Ann Rheum Dis 1993; 52: 215-218)

Reports of pain related to rheumatoid arthritis (RA) often include the shoulder; $40 \%$ of patients are affected early in the disease and nearly all eventually have shoulder pain. ${ }^{1}$ In addition, other causes of shoulder pain, especially rotator cuff disease, are a major cause of morbidity. Shoulder disease produces night pain which interrupts sleep, adds further stress to the patients, and lowers their pain tolerance and quality of life. The primary site at which the shoulder is affected in patients with RA is the glenohumoral joint for which pain relief is often unsatisfactory and joint replacement is not yet routinely available. We have previously shown that blocking the suprascapular nerve (which provides sensory fibres to about $70 \%$ of the shoulder joint) using a mixture of bupivacaine $0.5 \%$ and adrenaline (Ba) plus $40 \mathrm{mg}$ methylprednisolone $(\mathrm{P})$ results in a considerable improvement in pain relief and range of movement compared with intra-articular injection. ${ }^{2}$ As there are disadvantages to using steroids and their indication is not clear, we carried out a double blind study to determine whether the conventional mixture of $\mathrm{Ba}+\mathrm{P}$ was more effective than $\mathrm{Ba}$ alone.

\section{Subjects and methods}

Twenty nine patients (20 women) were recruited for the study. The median age was 60 years (range 26-73) and the mean disease duration was 13 years (range 5-26). One patient was withdrawn after three weeks because of developing intractable pain due to cervical spondylosis and two were lost to follow up after eight weeks (one because of pneumonia and one did not attend because of travelling distance). Thus 26 patients (18 women) and 52 shoulders completed the follow up study. Inclusion criteria were: $(a)$ chronic RA fulfilling the 1987 American Rheumatism Association criteria; (b) bilateral painful restricted shoulder movements; and (c) no response to an intra-articular corticosteroid injection in the last four months.

Patients were excluded if they had shoulder pain due to cervical spondylosis or if they had clinically active RA.

Suprascapular nerve block (SSNB) was performed on one side using $2 \mathrm{ml} \mathrm{Ba} 0.5 \%$ and on the other side with $2 \mathrm{ml} \mathrm{Ba} 0.5 \%$ plus $1 \mathrm{ml}$ $40 \mathrm{mg} \mathrm{P}$ (total volume $3 \mathrm{ml}$ ). The treatment was randomised for the side most severely affected. Thirty envelopes ( 15 containing cards of $\mathrm{Ba}+\mathrm{P}$ and 15 with cards of $\mathrm{Ba}$ ) were shuffled. One envelope was allocated for each patient which determined the type of treatment for the side most severely affected. The other side received the other treatment. Syringes were filled and wrapped in foil paper by one investigator so that injections and assessment were performed blindly by the other. We used $10 \mathrm{ml}$ syringes to 'hide' the difference in volume between the two treatments. The technique described by Carron et al ${ }^{3}$ was followed with modification so that half the injection was given into the suprascapular notch and the other half to the branches of suprascapular nerve distal to this site.

With the patients in a sitting position, the two ends of the spine of the scapula were located and a line drawn along the upper borders of the spine (fig 1). After local skin anaesthesia a $5 \mathrm{~cm}$ needle (not spinal as recommended) was advanced perpendicular to two planes until it touched bone in the intaspinous fossa where a negative aspiration was ensured using an empty syringe. 
Approximately half of the nerve block drug was injected into the supraspinous fossa (to block the branches of the suprascapular nerve). The

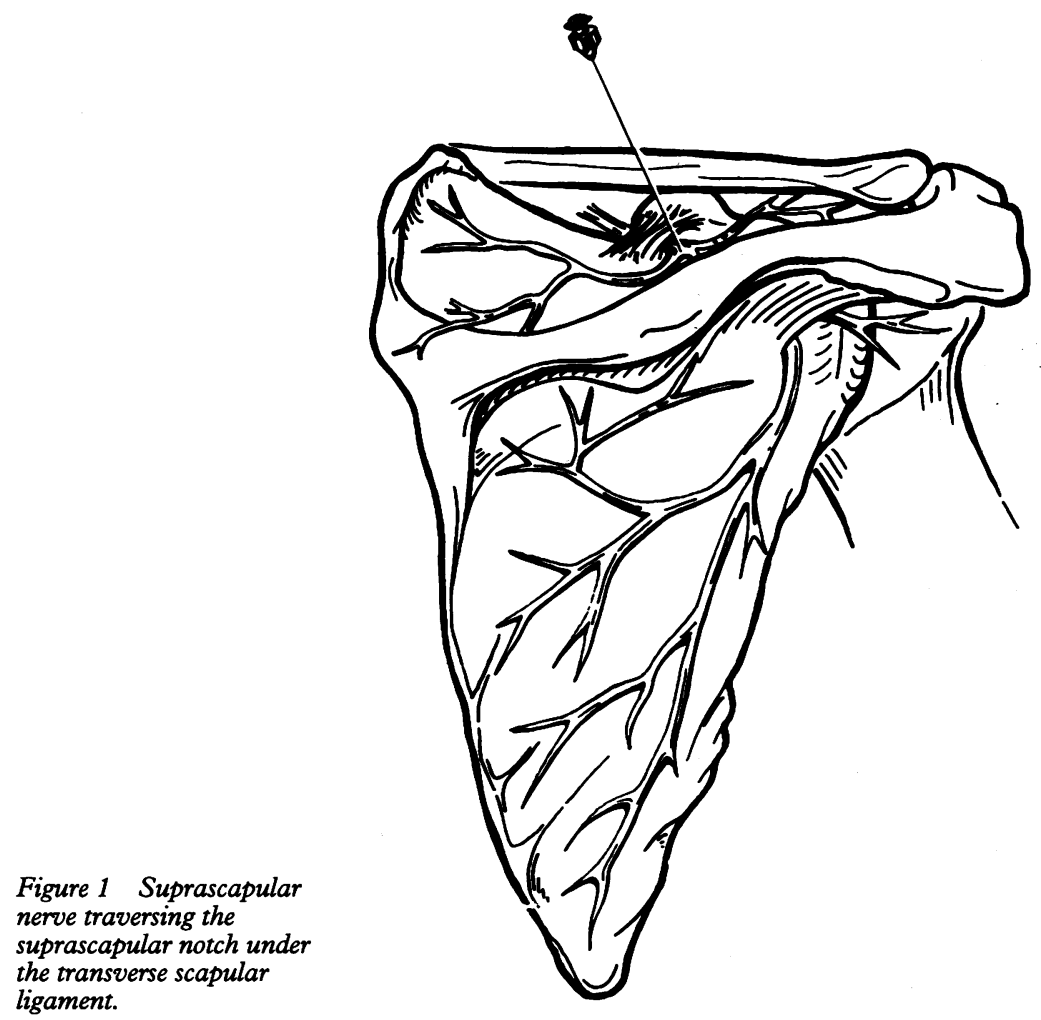

Effect of SSNB using bupivacaine $0.5 \%$ and adrenaline $(\mathrm{Ba})$ alone and $\mathrm{Ba} 0.5 \%$ plus methylprednisolone $(P)$ on pain, stiffness, and range of movement in patients with rheumatoid arthritis and chronic shoulder pain. Results shown express mean (standard error) percentage values of 29 patients at zero and one week, 28 patients at four weeks and 26 patients at 12 weeks. Figures between the braces \{ \} express absolute (standard error) values in millimetres for VASP and VASS and in degrees for movement at time zero. Comparing values at times 1,4, and 12 weeks with those at baseline, all were significantly improved $(p<0.001)$ with the exception of those marked ${ }^{\star}(p<0.05)$ or + (difference not significant). Comparing values for $B a$ alone with those for $B a+P$, all values were insignificant except those marked $\ddagger$ where $B a$ alone produces significantly $(p<0.05)$ greater improvement

\begin{tabular}{|c|c|c|c|c|}
\hline & \multicolumn{4}{|c|}{ Weeks after injection } \\
\hline & 0 & 1 & 4 & 12 \\
\hline \multicolumn{5}{|c|}{ Pain (VAS) $(\%)\{\mathrm{mm}\}$} \\
\hline $\begin{array}{l}\mathrm{Ba} \\
\mathrm{Ba}+\mathrm{P}\end{array}$ & $\begin{array}{l}100\{60(3 \cdot 7)\} \\
100\{60(3 \cdot 5)\}\end{array}$ & $\begin{array}{l}59(5) \\
61(6)\end{array}$ & $\begin{array}{l}47(5) \\
59(5)\end{array}$ & $\begin{array}{l}58(7) \\
64(7)\end{array}$ \\
\hline \multicolumn{5}{|c|}{ Stiffiness (VAS) $(\%)\{\mathrm{mm}\}$} \\
\hline $\begin{array}{l}\mathrm{Ba} \\
\mathrm{Ba}+\mathrm{P}\end{array}$ & $\begin{array}{l}100\{60(5 \cdot 4)\} \\
100\{60(6 \cdot 2)\}\end{array}$ & $\begin{array}{l}54(6) \\
59(7)\end{array}$ & $\begin{array}{l}54(6) \\
61(7)\end{array}$ & $\begin{array}{l}53(7) \ddagger \\
63(7)\end{array}$ \\
\hline \multicolumn{5}{|c|}{ Movement (\%) \{degrees\} } \\
\hline \multicolumn{5}{|c|}{ Flexion } \\
\hline $\begin{array}{l}\mathrm{Ba} \\
\mathrm{Ba}+\mathrm{P}\end{array}$ & $\begin{array}{l}100\{66(4 \cdot 6)\} \\
100\{66(4 \cdot 5)\}\end{array}$ & $\begin{array}{l}127(5) \\
115(5)\end{array}$ & $\begin{array}{l}127(5) \\
117(6)\end{array}$ & $\begin{array}{l}123(6) \\
108(5)\end{array}$ \\
\hline \multicolumn{5}{|l|}{ Passsive } \\
\hline $\begin{array}{l}\mathbf{B a} \\
\mathbf{B a}+\mathbf{P}\end{array}$ & $\begin{array}{l}100\{78(4 \cdot 1)\} \\
100\{76(4 \cdot 2)\}\end{array}$ & $\begin{array}{l}121(5) \\
119(3)\end{array}$ & $\begin{array}{l}121(5) \\
120(4)\end{array}$ & $\begin{array}{l}115(4) \\
115(4)\end{array}$ \\
\hline \multirow{2}{*}{\multicolumn{5}{|c|}{$\begin{array}{l}\text { Extension } \\
\text { Active }\end{array}$}} \\
\hline & & & & \\
\hline 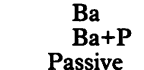 & $\begin{array}{l}100\{48(2 \cdot 6)\} \\
100\{49(2 \cdot 5)\}\end{array}$ & $\begin{array}{l}134(8) \\
126(6)\end{array}$ & $\begin{array}{l}134(7) \\
130(6)\end{array}$ & $\begin{array}{l}129(5) \\
128(5)\end{array}$ \\
\hline \multicolumn{5}{|l|}{ Passive } \\
\hline $\begin{array}{l}\mathbf{B a} \\
\mathbf{B a}+\mathbf{P}\end{array}$ & $\begin{array}{l}100\{55(2 \cdot 9)\} \\
100\{54(2 \cdot 9)\}\end{array}$ & $\begin{array}{l}127(6) \\
127(6)\end{array}$ & $\begin{array}{l}125(6) \\
129(6)\end{array}$ & $\begin{array}{l}121(6) \\
123(6)\end{array}$ \\
\hline \multirow{2}{*}{\multicolumn{5}{|c|}{$\begin{array}{l}\text { Abduction } \\
\text { Active }\end{array}$}} \\
\hline $\begin{array}{l}\text { Aoduction } \\
\text { Active }\end{array}$ & & & & \\
\hline $\begin{array}{c}\mathbf{B a} \\
\text { Ba+P } \\
\text { Passive }\end{array}$ & $\begin{array}{l}100\{52(2 \cdot 8)\} \\
100\{55(3 \cdot 4)\}\end{array}$ & $\begin{array}{l}138(11) \ddagger \\
110(5)\end{array}$ & $\begin{array}{l}135(12) \\
111(5)\end{array}$ & $\begin{array}{l}132(15) \\
108(5)\end{array}$ \\
\hline \multicolumn{5}{|l|}{ Passive } \\
\hline $\begin{array}{l}\mathrm{Ba} \\
\mathrm{Ba}+\mathbf{P}\end{array}$ & $\begin{array}{l}100\{62(3.0)\} \\
100\{62(3.4)\}\end{array}$ & $\begin{array}{l}124(5) \\
115(3)\end{array}$ & $\begin{array}{l}121(5) \\
115(3)\end{array}$ & $\begin{array}{l}117(4) \\
114(3)\end{array}$ \\
\hline \multicolumn{5}{|c|}{$\begin{array}{l}\text { Ext Rotation } \\
\text { Active }\end{array}$} \\
\hline $\mathrm{Ba}$ & $100\{33(3 \cdot 8)\}$ & $133(18)$ & $126(19)^{\star}$ & $109(9) \dagger$ \\
\hline $\begin{array}{r}\mathbf{B a}+\mathbf{P} \\
\text { Passive }\end{array}$ & $100\{34(3 \cdot 8)\}$ & $119(11)$ & $117(11)$ & $111(11)$ \\
\hline $\begin{array}{l}\mathrm{Ba} \\
\mathbf{B a}+\mathbf{P}\end{array}$ & $\begin{array}{l}100\{35(4 \cdot 0)\} \\
100\{36(4 \cdot 0)\}\end{array}$ & $\begin{array}{l}122(10) \\
129(15)\end{array}$ & $\begin{array}{l}118(13)^{\star} \\
126(15)\end{array}$ & $\begin{array}{l}112(11)^{\star} \\
119(14)^{\star}\end{array}$ \\
\hline
\end{tabular}

needle was withdrawn to the subcutaneous level, redirected $15^{\circ}$ cephalad and laterally and advanced again to reach the free edge of bone in the suprascapular notch, where the rest of the blocking agent was injected. Mild pain felt by the patient at the shoulder tip radiating down the arm during injection denoted proper location.

Patients were examined by the assessor blind to treatment before the injection and at 1,4 , and 12 weeks. Pain and stiffness were assessed using visual analogue scales (VASP and the VASS respectively) where 0 denotes no pain and $10 \mathrm{~cm}$ denotes the most severe degree of pain or stiffness. Active and passive total movement were measured using a goniometer.

Statistical analysis was performed using the Wilcoxon matched pairs signed rank test.

\section{Results}

The table shows VASP, VASS, and range of total movement at $0,1,4$, and 12 weeks. The pre-injection mean in week 0 (baseline values) was taken as $100 \%$. Both treatments were successful in the main outcome measures. Measures of pain and stiffness showed a highly significant improvement compared with baseline $(p<0.001)$, which was maintained throughout the three follow up visits. Improvement in the VAS of pain in the Ba group was 41,53 , and $42 \%$ (for weeks 1,4 , and 12 respectively) whereas in the $\mathrm{Ba}+\mathrm{P}$ group it was 39,41 , and $36 \%$. Comparable improvements were also seen in stiffness in the group treated with $\mathrm{Ba}$ alone, showing, 46, 46 and $47 \%$ improvement, whereas SSNB using $\mathrm{Ba}+\mathrm{P}$ achieved 41,39 , and $37 \%$ improvement. Although the improvement in pain and stiffness favoured the treatment with $\mathrm{Ba}$ alone, there was no statistically significant difference between the two treatments except in stiffness at week $12(p<0.05)$. The effect on movement was of interest. Flexion, extension, and abduction (active and passive) showed a highly significant improvement compared with baseline $(p<0.001)$ which was maintained for up to 12 weeks. The improvements in these three movements were greater in the group treated with $\mathrm{Ba}$ alone (with the exception of passive extension at weeks 4 and 12), the difference reaching statistical significance in active abduction at week $1(\mathrm{p}<0 \cdot 05)$. Figures 2 and 3 show the effect of the two treatments on pain, stiffness, and active movements.

\section{Discussion}

Suprascapular nerve block is a valuable method to control shoulder pain. We have previously shown that SSNB using the conventional mixture of $\mathrm{Ba}+\mathrm{P}$ was superior to an intra-articular steroid injection in patients with RA with chronic shoulder pain. ${ }^{2}$ The aim of this study was to investigate the value of the $\mathrm{P}$ component in the SSNB mixture. The two treatments were successful in the main outcome measures. Considerable improvement in pain and stiffness was achieved and maintained until the end of the study. At week 

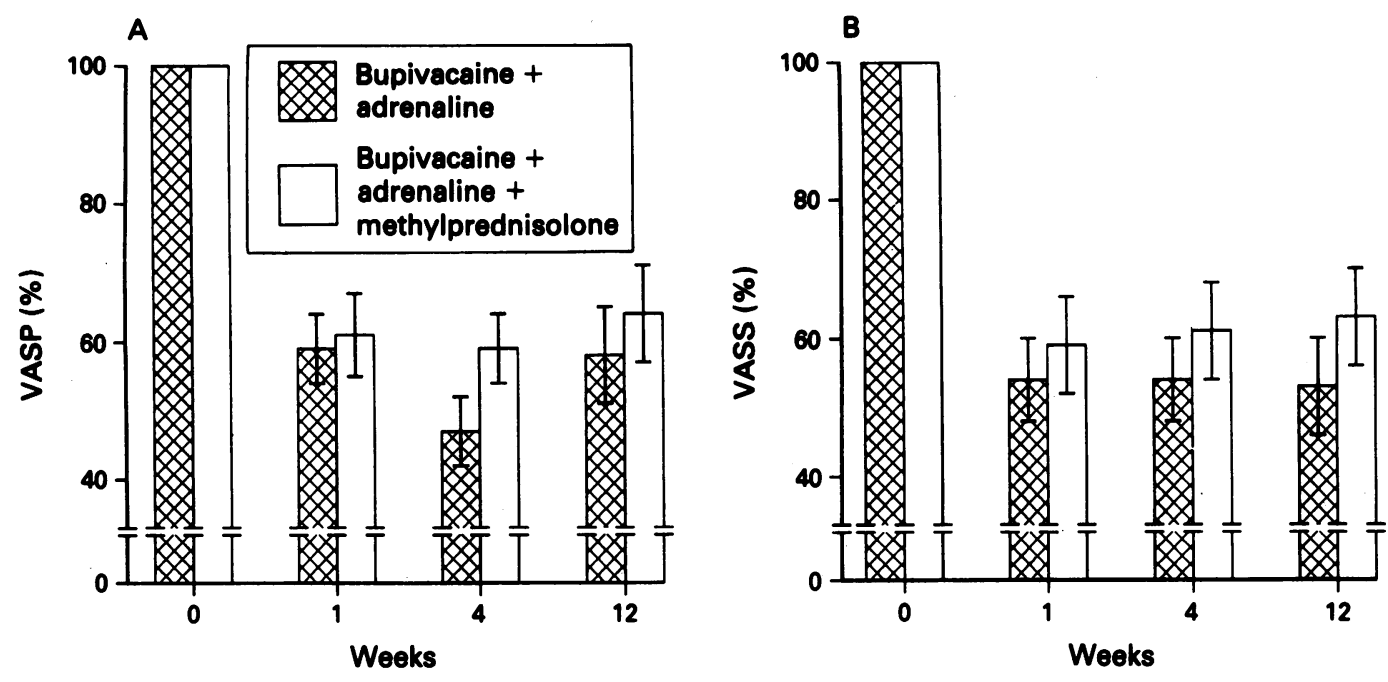

Figure 2 Effect of suprascapular nerve block on $(A)$ pain and (B) stiffness measured by visual analogue scales (VASP and VASS respectively). Results are expressed as percentage change of week 0 (100\%) and are mean (standard error) values. Highly significant improvements $(p<0.001)$ were noted at all follow up visits compared with week 0 values. No significant difference was noted when comparing the two treatments except for stiffness at week $12(p<0 \cdot 05)$.
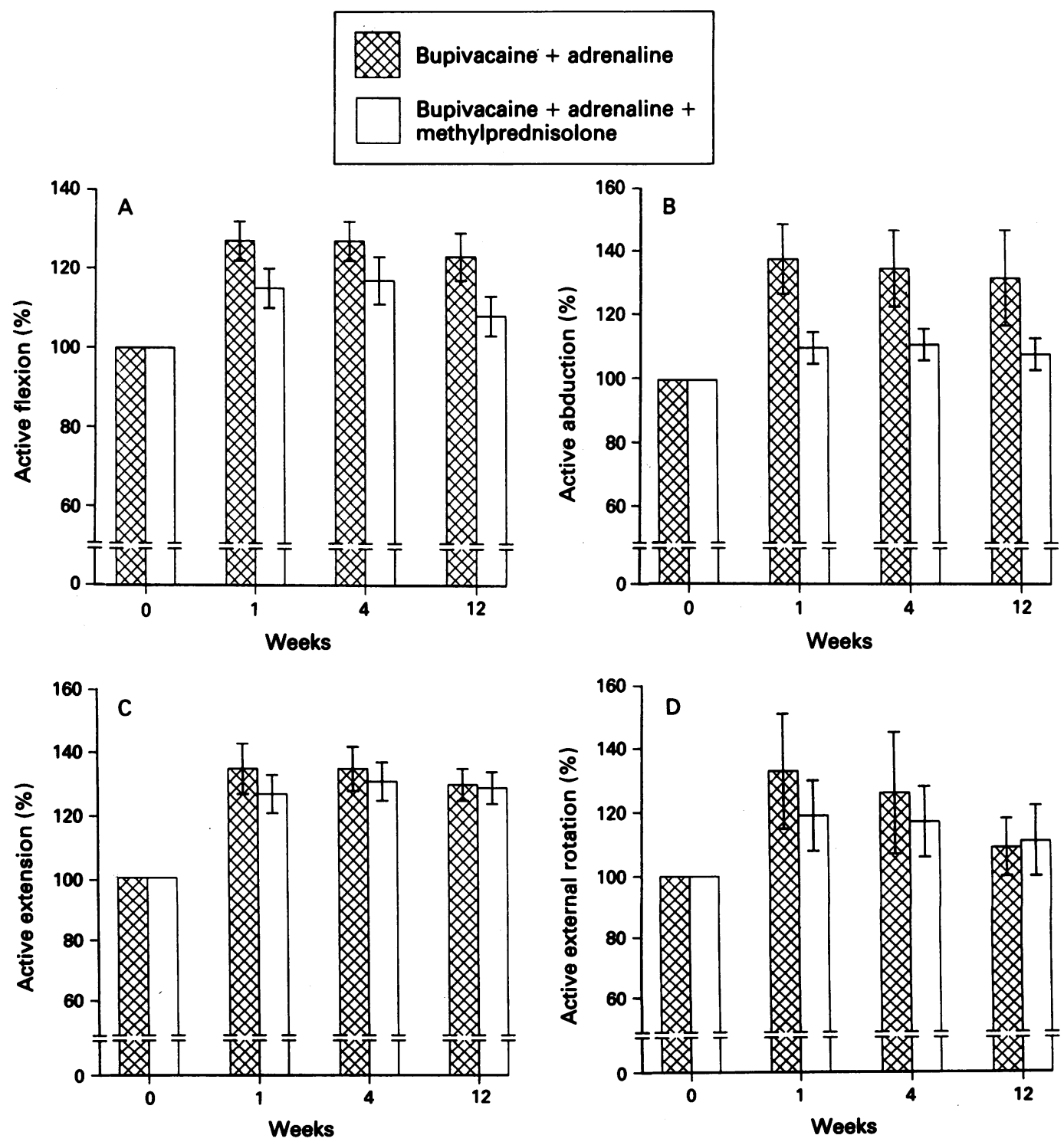

Figure 3 Effect of suprascapular nerve block on active flexion $(A)$, abduction $(B)$, extension $(C)$, and external rotation (D). Results are expressed as percentage change of week 0 (100\%) and are mean (standard error) values. Highly significant improvements $(p<0.001)$ were noted at all follow up visits compared with week 0 values except for Ba alone group at week 12 for external rotation (for $p$ values, see table). No significant difference was noted between the two treatments except for active abduction at week $1(p<0 \cdot 05)$. 
12 , the improvement of pain was $42 \%$ for $\mathrm{Ba}$ alone and $36 \%$ for $\mathrm{Ba}+\mathrm{P}$. At the same time improvement in stiffness was 47 and $37 \%(\mathrm{Ba}$ alone and $\mathrm{Ba}+\mathrm{P}$ respectively). Comparable improvements were also noticed in most movements. The only significant differences favoured using the $\mathrm{Ba}$ injection alone. It is notable that some patients showed improvement for up to eight months after this injection (unpublished observation). It is known that the pain relieving effects of regional anaesthetic block often outlast its pharmacological impulse blocking effect. This prolonged analgesic effect may be due to an effect on $C$ fibres that interrupts the cycle of feedback amplification that can occur in chronic pain. ${ }^{56}$ The high concentration of local anaesthetic used $(0.5 \%$ bupivacaine) may also have made a difference. ${ }^{5}$ The highly significant improvements seen in this study may also have reflected the modified technique used. The blockade of additional branches of the suprascapular nerve may increase the effectiveness either because the fibres contribute to the conduction of shoulder pain or because the blockade provides some analgesia in patients where the main trunk is missed owing to anatomical variation.

As previously noted ${ }^{2}$ rotation was the outcome least responsive to SSNB. In addition, active rotation was the one movement which seemed to be helped more by $\mathrm{Ba}+\mathrm{P}$ and where the improvement with $\mathrm{Ba}$ alone was not significant when compared with baseline. It may be that rotation is restricted more by the inflammatory disease process in patients with RA than by pain alone. Alternatively, the anterior capsule, which is not innervated by the suprascapular nerve, may be used more in rotatory movement.

The improvement achieved in active abduction deserves special attention. The suprascapular nerve provides the only motor nerve supply to the supraspinatus and infraspinatus muscles. The improvement in active abduction confirms that a clinically important motor neuropathy did not occur. No significant side effects were noted; in particular pneumothorax and injury of the posterior cord of brachial plexus were not observed either in this study or in 150 subsequent blocks. We believe that using a shorter $5 \mathrm{~cm}$ long needle (instead of the spinal needle traditionally recommended) may have helped to avoid such complications.
This study was set up to evaluate the $P$ component of a mixture for SSNB. Sham SSNB using $0.9 \%$ saline was performed in our previous study but not in this study as only two SSNBs can be performed in any subject (one for each shoulder) and a direct comparison of the two active treatments was desired. One unavoidable consequence of giving two injections to the same subject was that the side receiving $\mathrm{Ba}$ alone was exposed to some extent to systemically absorbed steroids. These patients were known to be resistant to intraarticular steroids, however, which would produce the same systemic effect. Furthermore, any systemically absorbed steroids from the SSNB would have resulted in a low serum level and would be unlikely to produce a better result on the $\mathrm{Ba}$ only side.

It is clear that under the conditions of this study, the addition of $\mathbf{P}$ confers no additional benefit over blocks performed with $\mathrm{Ba}$ alone. This has important implications as $\mathrm{Ba}$ alone as an injection can be repeated as required without the potential disadvantages of steroid administration. Thus, not only can patients with chronic pain receive repeated injections as indicated, but the absence of exposure to steroids with SSNB means that in patients with acute shoulder pain, SSNB with Ba alone can be administered alone or used in conjunction with intra-articular steroids. This has the potential to prevent the development of regional pain or frozen shoulder syndrome from more localised shoulder disorders.

We thank Dr Ronald Jubb and Professor Paul Bacon for allowing us to enter their patients in the study. This work was sponsored by a grant from the British Council and the Arthritis and Rheumatism Council, United Kingdom.

1 Petersson C J. Painful shoulders in patients with rheumatoid arthritis. Scand $\mathcal{F}$ Rheumatol 1986; 15: 275-9.

2 Emery P, Bowman . S, Wedderburn L, Grahame R. Suprascapular nerve block for chronic shoulder pain in rheumatoid arthritis. BMF 1989; 299: 1079-80.

3 Carron H, Korbon G A, Rowlingson J C, eds. Regional anaesthesia. Techniques and clinical applications. New York: Grune and Stratton, 1985: 145-8.

4 Arnett F C, Edworthy S M, Bloch D A. The American Arnett F C, Edworthy S M, Bloch D A. The American
Rheumatism Association, 1987. Revised criteria for the classification of rheumatoid arthritis. Arthritis Rheum 1988; 31: 315-23.

5 Gerbershagen $\mathrm{H}$ U. Blocks with local anaesthetics in the treatment of cancer pain. In: Bonica J J, Ventafridda V, eds. Advances in pain research and therapy. Vol. 2. New York: Raven Press, 1979: 311-23.

6 Bonica J J. Introduction to nerve blocks. In: Bonica J J, Ventafridda V, eds. Advances in pain research and therapy. Vol. 2. New York: Raven Press, 1979: 303-10. 